\title{
REVIEW PAPER ON WASTEWATER TREATMENT PLANT USING PLC \& SCADA
}

\author{
Ankit R. Rajhans, Sumit S. More, Saurabh V. Gambhir, Vaibhav H. Deshmukh \\ Department of Electrical Engineering \\ Vishwaniketan Institute of Management and Engineering Technology. \\ Mumbai- 410202, India \\ Prof. Sarthak k.Joshi \\ (Assistant Professor) \\ Department of Electrical Engineering \\ Vishwaniketan Institute of Management and Engineering Technology. \\ Mumbai- 410202, India
}

\begin{abstract}
-
This paper reviews a very basic and effective method of waste water treatment employed in industries as well as domestic applications. The Treatment process involves four basic steps or stages to purify water so as to use it to required applications, they are Bar-screening, Coagulation, pH adjustment and chlorination stage. The research work majorly focuses on the monitoring and controlling of the waste water treatment by employing PLC and SCADA. PLC and SCADA makes the entire process automatic and reliable with high supervision.

This research work improves the overall efficiency of conventional waste water treatment plant, by injecting appropriate amount of chemicals into the water as per the requirement. On the other hand, Reliability of the conventional plant is also taken care of by employing high-speed protective devices to avoid any fault introducing in the system.

The real time simulation of the entire operation is displayed on the SCADA screen. This feature of the waste water treatment plant is of utmost importance to analyze even minute details of the system.
\end{abstract}

Keywords - Programmable logic controller (PLC), Automation, Waste-water, Supervisory Control and Data Acquisition System (SCADA).

\section{INTRODUCTION}

Waste water is generated from many industrial as well as domestic applications. Typical residential water usage is from 150 to 200 liters per person per day. SeventyTwo percent of the population is linked to a centralized wastewater plant and treatment system, while the remaining 27 percent uses on-site septic systems. The water flows after washing becomes wastewater better known as sewage that must be cleaned up before it is returned to the environment for reuse. In some way or the other ways, sufficient amount of water is recycled. Earlier In the past, People would think that there is no way of reusing the water after it is used since there was no advancement in the technology and no effective ways of waste water treatment available. However, nowadays different waste water processes are available and that too employing different technologies. Purifiers implementing plasma technology, reverse osmosis technology, uv ray light technology, etc. are available in the market.

Here, we introduce simple and quite effective waste water purifier with four stages such as filtration, coagulation, chlorination and $\mathrm{pH}$ adjustment stage. This whole consists of different sensors and other automatic operative devices make purifier work automatic and efficient. Moreover, SCADA technology employed here helps to get the real time simulation of the process with effective control of the plant from the control room. Leakage sensors, solenoid valves, peristaltic pump are also connected and properly interfaced to the PLC, so that reliability would not be compromised.

As due to increase in the population world wide, the strain on the environmental resources will increase which would eventually lead to a greater harm to available water resources. Today, Population is increasing at a very high rate, this will significantly lead to water crisis as increasing population would not cope with the existing water resources, and this will cause several health problems, failure in the agricultural activities, loss in the economical development, etc.

Modern civilisations integrated with rapidly advancement in technology and fast growing economic system is harmful from its own activities causing water pollution. India is the seventh largest country in the world with a total geographical area of 3.29 million sq. $\mathrm{km}$ with a population of approx 1.30 billion, around $30 \%$ of the population live in urban areas spread over 5000 towns. However, India is one of the growing economies in the world with a drastic development in the field of science and technology. This unregulated and uncontrolled development of the country, leads to significant stress on the sewage system as waste water is produced in high quantum everyday. This leads to a difficulty in the waste water treatment planning. Aerobic activated sludge reactors have been employed on a limited scale as bio-scrubbers for treating odorous air. Despite plenty of positive reports from 
full scale applications in North America, small data is available on the actual performance of these methods with wide ranging concerns on mitigation of settling efficiency due to changes in filamentous organisms and bacterial flocks. These issues are alleviated in MBRs where gravitational diffusion of the microbial solution is changed by mechanical filtration. Also, the settling and bioconversion of odorous gases are a function of contact period, bubble volume, and reactor configuration. Submerged MBRs facilitates the membrane unit within the bioreactor and depends on gas and liquid scouring to keep the membrane surface clean. Since modern livestock processes are equipped with fans, blowers and ventilation systems, booster fans could be integrated to increase outflow air pressure. This concept was found in past research efforts, when biofilter were checked for odour removal.

\section{- Water scarcity problems:}

Due to increase in the population of the country and economical development, there is a threat to the human beings due to scarcity of water as waste water is generated everyday in a very large amount. Hence, efforts to be made in order to recycle and reuse the waste water by conducting certain treatment methods, so as to reuse waste water for domestic, industrial, municipal and agricultural activities. By doing this, there will be less strain on the environment and effective sustainable development.

\section{- Options available to reuse wastewater are as follows:}

1. Desalination of wastewater

2. Recycle and reuse of wastewater or sewage

3. Implementation of different measures to conserve water

4. Implementation of different projects to harvest rainfall. (Dams and reservoirs)

- Factors responsible for contaminating water:

1. Oil pollution

2. Industrial waste Recycle and reuse of wastewater or sewage

3. Wastewater and sewage

4. Radioactive waste

5. Global warming

6. Marine Dumping

7. Atmospheric deposition

\section{- Types of pollutants:}

1. Domestic- The Wastewater generated by accomplishing all the household activities like cooking, toilet flushing, cleaning, washing, etc. is termed as domestic waste or pollutant. By properly treating this wastewater, this can be reused again for doing future activities.
2. Industrial/ Municipal/ Agricultural- The Wastewater which is generated by the industries such as processed industries, pharmaceutical industries, food industries, etc. is termed as industrial waste. Similarly, waste water produced from agricultural and municipal activities is termed as agricultural and municipal waste. Municipal waste includes public toilets cleaning, public transport cleaning, etc.

\section{- Contaminants in Wastewater and their importance:}

\section{Pathogenic organisms}

Importance- These are present in Wastewater or sewage and cause several infectious diseases.

\section{Suspended solids}

Importance- These lead to formation of sludge in the wastewater tank and if water containing suspended particles are discharged directly into rivers, lakes, etc. it affects the aquatic environment significantly.

\section{Heavy metals}

Importance- These are toxic in nature and detrimental to the environment.

4. Dissolved inorganic constituents

Importance- Inorganic constituents such as calcium, sulphate and sodium are initially mixed to the domestic water supplies and while reusing the wastewater, it has to be removed.

\section{- Requirement of wastewater treatment:}

Wastewater treatment needs decomposition of complex organic impurities in the wastewater into simple and basic compounds that are stable and impurity-free. The harmful impact on the environment if waste water is not treated properly and disposed into the existing water resources are as mentioned below:

1. Harmful gases are produced when the organic compounds in the waste water are broken down and those gases then affect the stability of the environment.

2. Sewage consisting a large amount of organic impurity, if discharged into a river / lakes, will absorb the oxygen present in the water and this significantly deplete the dissolved oxygen of the stream, which endangers the life of aquatic creatures and other harmful effect on the environment.

3. Wastewater may also contain organic nutrients, which can improve the growth of aquatic plants and algal blooms, thus leads to growth of plants in the lakes and streams. 
4. Untreated sewage usually contains number of microorganisms or disease causing bacteria and toxic compounds, that goes into the human intestinal tract or may be present in certain industrial waste water. These may pollute the land or the water body, where such waste water is disposed.

Therefore, the treatment and disposal of wastewater if of utmost importance and hence necessary to keep the environment stable.

\section{- Current scenario of wastewater in India:}

The total wastewater produced by 299 tier- 1 cities is 16,652.5 MLD. Out of this, about $60 \%$ is produced by 23 metro cities. The state of Maharashtra alone contributes approx $25 \%$ while the Ganga river basin contributes about $30 \%$ of the total wastewater generated in tier-1 cities. Only about $72 \%$ of the total treated wastewater generated is collected. Out of 299 tier-1 cities, 160 cities have sewage system for more than 75 percent of population and 92 cities cover more than $50 \%$ of the population. On the whole $70 \%$ of total population of tier-1 cities is provided with sewage facility, compared to $48 \%$ in 1988. The type of sewage system is either open or closed or piped. The main purpose of this study was to carry out a review of the treatment of domestic waste water using the aerobic sludge to ensure effective discharge.

\section{- Treatment of Wastewater in India:}

Out of 16,662.5 MLD of wastewater produced, only 4037.2 mld $(25 \%)$ is treated before release, the rest (i.e. 12,626.30 MLD) is disposed without proper treatment. Only 27 cities have primary waste water treatment facilities and only 49 cities have primary and secondary treatment facilities.

\section{- Industrial, Domestic and Municipal recycling of Wastewater:}

Municipal uses of treated wastewater include the irrigation of road constructions, gardens and parks, grounds and stadiums, golf courses and toilet cleaning, etc. Industrial recycling of wastewater include cooling systems, steam generation in case of thermal power plant and other applications where water is utilised. Agriculture utilises the food processing industry and other applications. In Middle Eastern countries, where water is limited, dual distribution systems will, in the future, provide high quality, treated waste water for toilet flushing to restaurants, office buildings, etc.

In India, wastewater is currently being used for irrigation, gardening, cleaning, cooling of AC systems, as a feed for boilers to generate steam. In China, national policy has been implemented that promotes the development of water-efficient technologies, and encourages the recycle of municipal sewage in agriculture and then for municipal and industrial applications. In Japan, municipal or industrial wastewater is used for toilet cleaning, industrial applications and restoration of streams, etc.

The considerations to be made regarding the technologies used for wastewater treatment are as follows-

1. The technology used for the wastewater treatment should be simple, low cost, and should require low energy for its operation with no harm to the environment and the people.

2. The technology employed should take care of the public as well as the environment health. It should not endanger human's lives due to its use.

3. The technology employed in the plant should be easy to use for the labours and the chemicals as well as the components required in the plant should not be too expensive to afford.

4. The technology used should be such that, it can be upgraded easily as per the user's demand or some quality standards in future.

\section{- Wastewater treatment methods:}

1. Physical methods- These involves physical forces to remove sediments present in the waste water.

1) Sedimentation- This is a widely used method employed in existing wastewater treatment. This uses gravitational settling of the impurities by proper techniques, and mostly, coagulation along with sedimentation is used to deposit impurities at the bottom of the tank.

2) Floatation- Here, air bubbles are introduced, which helps to eradicate physical and liquid impurities present in the waste water. This works on the principle of buoyancy.

Environmental applications of floatation:

1) Wastewater with heavy metals and anions treatment

2) Removal of calcium and anions

3) Acid mine drainage system

4) Soil treatment

Industrial applications of floatation:

1) Domestic and industrial treatment of water

2) Sewage treatment

3) Microorganisms removal treatment 
2. Mechanical methods- These physically separates solid impurities present in the waste water.

1) Screening- This separates the solid impurities present in the waste water by effective screening so as to protect the primary tank from damage, and send properly screened water to the next stage.

2) Filtration- This is rather a biological method to filter out the solid as well as dissolved impurities present in the waste water. This method is widely used in domestic water purifiers.

\section{Biological Methods-}

1) Chlorination- This is employed to eliminate the pathogens and other microorganisms which are harmful for the water to be used, and hence they are treated properly. This also takes care of the odour and the colour of the waste water by adding injecting chlorine into it.

2) Dechlorination- This removes the chlorine which remains in the water after chlorination by adding reducing agents such as sulphur dioxide and sodium sulphide.

4. Membrane filtration methods- This method effectively filters out any metal or solid impurity present in the waste water.

1. Reverse osmosis- This is a widely used method nowadays, due to its high efficiency of filtering mineral substances as well as low molecular organic compound. This uses semi-permeable membrane, through which waste water passes and impurities are filtered out by the membrane, due to its pore size.

Ultra filtration, Nano filtration, Reverse osmosis and electro dialysis are the methods used to filter out suspended, colloidal and other metal particles present in the waste water. It also filters out low molecular and micro molecular organic compounds.

Adsorption- This is one of the greatest of all the technologies existing today for wastewater treatment and widely used in almost all the industrial applications. This is an effective method as it is simple, efficient and eco-friendly method. Basically, this is a mass transfer technique wherein metal ions are transferred from the solutions of wastewater to the surface of sorbent and becomes bound by chemicals and physical interactions.

- Advantages and disadvantages of different wastewater treatment technologies-

\section{Biological process:-}

- Advantages-

a) Process is ecologically favourable.

b) Economical operation.

c) Availability and operation is easy in nature.

- Disadvantages:-

a) Capital cost and operational cost is comparatively high.

\section{Adsorption:-}

- Advantages-

a) Process is entirely profitable.

b) Efficient method.

c) Eco-friendly method.

- Disadvantages

a) Pollutant is merely eradicated from one stage to another.

b) Regeneration process is expensive.

\section{Ozone process:-}

- Advantages-

a) Large no. of organic and inorganic compounds are powerfully oxidised.

- Disadvantages-

b) More complex technology, requires high capital and operational cost.

c) High electricity consumption.

\section{UV light method:-}

- Advantages:-

a) It does not leave any byproduct detrimental to the environment.

b) Effective method.

- Disadvantages-

a) Less effective if wastewater particles absorb UV light.

b) High operational cost. 


\section{International Journal of Engineering Applied Sciences and Technology, 2020 \\ Vol. 4, Issue 12, ISSN No. 2455-2143, Pages 667-671 \\ Published Online April 2020 in IJEAST (http://www.ijeast.com)}

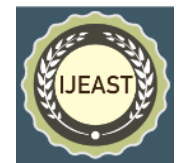

\section{CONCLUSION}

Here, Importance of water in the human existence is reviewed with different strategies to stabilize our environment by reusing the wastewater. Different wastewater treatment methods have been discussed, both conventional and non-conventional methods, and major stress is put on adsorption method which is concluded as the best method nowadays available for wastewater treatment as it is implemented in several applications.

\section{REFERENCES}

1) Bode R, Lee SH (2008) A review of studies on micellar enhanced ultrafiltration and Activated Carbon Fibre Processes. Environmental Engineering Research 13 (2) : 98 - 104.

2) Chakinala AG, Gogate PR., Burges AE, Bremner DH (2009) Industrial wastewater treatment.

3) J. Bouza-Fernandez, G. Gonzalez-Filgueira, S. de las Heras Jimenez, D.Vazquez-Gonzalez, "Expert System of a Sewage Treatment Plant for Wood Industry" (IEEE, 2010).

4) Bode R, Lee SH (2011) A review of studies on micellar enhanced ultrafiltration for heavy metals removal from wastewater. J Water Sustain 1:85102.

5) Bekiari V, Lianos P (2010) poly ( sodium acrylate ) hydrogels as potential $\mathrm{pH}$ - sensitive sorbents for the removal of model organic and inorganic pollutants fro water. Glob Nest J 12 (3) : $262-229$.

6) https://www.ijareeie.com/upload/2016/november/1 7_4_AUTOMATION.pdf, Anderson Elshaw; N. M. R. Hassan; M. M. K. Khan "CFD Modelling and Optimisation of a Waste Water Treatment Plant Bioreactor" -A Case Study 2016 3rd Asia-Pacific World Congress on Computer Science and Engineering (APWC on CSE).

7) https://www.engpaper.com/scada 2017.html https://www.ijireeice.com/upload/2017/may17/IJIREEI CE\%207.pdf

9) http://www.coyneenvironmental.com/wastewater treatment/water-treatment-applications/2018, https://www.researchgate.net/publication/31805670 3_PLC_and_SCADA_Based_Sewage_Water_Treat ment_Plant

10) https://ijedr.org/papers/IJEDR1901046.pdf, http://irejournals.com/formatedpaper/1700683.pdf, http://ciitresearch.org/dl/index.php/pdcs/article/vie w/PDCS052016007.

11) http://www.researchgate.net/publication/332183222 _Wastewater_Treatment_Methodologies_Review_ Article.

12) Technologies.pdf?origin=publication_detail.

13) Sadhguru. (2018, march 22). world economic forum. Retrieved from www.weforum.org: https://www.weforum.org/agenda/2018/03/theclean-sweep-cleaning-up-india-s-rivers/

14) Tandon, K., \& Sinha, A. (2007). Evaluation Of Operation And Maintenance Of Sewage Treatment
Plants In India-2007. CONTROL OF URBAN POLLUTION, 1-68.

15) Jamil, I., Jamil, R., Jamil, R., Jinquan, Z., \& Samee, A. (2013). Technical Communication of Automation Control System in Water Treatment Plant. International Journal of Innovation and Applied Studies ISSN 2028-9324 Vol. 4, 28-36.

16) Venkateswarlu, G., Sahu, J., Sriya, Y., \& Pappala, S. (2015, April). PLC and SCADA Based Secured and Sustainable Living. International Journal of Advanced Research in Electrical,Electronics and Instrumentation Engineering, 4, 1981- 1989. 